\title{
A REMOÇÃO COMO UM TIPO DE ESTRATÉGIA DE DEFESA COLETIVA DOS SERVIDORES DE UMA UNIVERSIDADE PÚBLICA
}

\author{
REMOVAL AS A TYPE OF COLLECTIVE DEFENSE \\ STRATEGY FOR PUBLIC UNIVERSITY SERVERS
}

Rosiane Valério de Moura ${ }^{1}$

Denilson Bezerra Marques²

1

Bacharel em Serviço Social (UFAL) e Mestre em Gestão Pública (UFPE)

2

Doutor em Sociologia

(UFPE) e Professor

Associado do Departamento

de Ciências Administrativas

e do Mestrado em

Gestão Pública da UFPE.

Psicanalista com graduação

(1995) e mestrado (2000)

em Administração pela

Universidade Federal

de Pernambuco.
RESUMO: O modelo de organização do trabalho ao qual estão submetidos os servidores de uma universidade pública aqui analisada é contraditório e determina vivências tanto de prazer quanto de sofrimento, levando-os a adotar estratégias de defesas para o enfrentamento das atividades laborais. Os resultados da pesquisa apontam que, para lidar com essa situação, os servidores constroem e utilizam estratégias e modos de enfrentamento para transformar o sofrimento em prazer e evitar o adoecimento. A metodologia utilizada para a coleta dos dados foi entrevista aberta com cada sujeito. A técnica de análise dos dados consistiu em uma análise qualitativa das narrativas apresentadas por cada sujeito a partir das entrevistas que concederam. Evidencia-se, através destas narrativas, que esses servidores enfrentaram conflitos interpessoais com os colegas de trabalho ou com seu chefe e utilizaram a remoção como forma de confrontação, como uma estratégia defensiva para lidar com esse sofrimento.

PALAVRaS-ChaVe: Organização do trabalho, psicodinâmica do trabalho, estratégia coletiva de defesa.

ABSTRACT: The work organization model to which the servants of a public university analyzed here are subjected is contradictory and determines experiences of both pleasure and suffering, leading them to adopt defensive strategies to cope with work activities. The results of the research indicate that, to deal with this situation, the servants build and use coping strategies and ways to transform suffering into pleasure and prevent illness. The methodology used for data collection was open interview with each subject. The data analysis technique consisted of a qualitative analysis of the narratives presented by each subject from the interviews they gave. It is evident from these narratives that these servants faced interpersonal conflicts with co-workers or their boss and used removal as a form of confrontation, as a defensive strategy to deal with this suffering.

KEYWORDs: Work organization, work psychodynamics, collective defense strategy. 


\section{INTRODUÇÃO}

O conceito de "trabalho" vem passando por mudanças significativas ao longo do tempo e os estudos sobre sua organização e sua relação com o homem como fonte de prazer/sofrimento vem ocupando lugar privilegiado nas reflexões teóricas atuais. A etimologia latina da palavra trabalho - "tripalium", instrumento de tortura feito com três paus - já denota algo penoso e indesejado, mostrando assim que a relação do homem com o trabalho sempre foi difícil.

A Psicodinâmica do Trabalho (PdT) tem tratado de questões relacionadas ao trabalho e sua relação com o prazer e sofrimento, envolvendo os aspectos psicossociais que interferem nos trabalhadores e nas organizações. Christophe Dejours oferece uma reflexão singular nas suas abordagens sobre a influência do trabalho na saúde mental dos indivíduos e trata das questões relacionadas à organização do trabalho e seus impactos sobre a saúde mental do trabalhador.

O objetivo deste estudo é identificar e analisar as estratégias de defesas coletivas construídas pelos servidores de uma universidade pública. Para responder a este objetivo, faremos uso de uma abordagem dos estudos da Psicodinâmica do Trabalho, como um modo de fazer análise crítica da organização do trabalho, causador de sofrimento, dada as particularidades da pós-modernidade, da acumulação flexível do capital e de todas as suas consequências para o mundo do trabalho.

Para a contextualização teórica deste trabalho, apresentamos um breve histórico sobre o conceito de trabalho, sua precarização e intensificação na sociedade capitalista. Apresentamos em seguida um item sobre a organização do trabalho, apontada pela PdT como fator principal das experiências de prazer e sofrimento do trabalhador. Analisaremos também os fundamentos de algumas categorias tratadas por Dejours na PdT, que investiga os mecanismos de defesa dos trabalhadores diante das situações que geram sofrimentos decorrentes da organização do trabalho.

\section{TRABALHO E FLEXIBILIZAÇÃO}

A incorporação de conceitos básicos da Sociologia do trabalho tem importância fundamental nos trabalhos de Dejours. Podemos citar como exemplo sua utilização dos modelos de gestão e de organização dos processos de trabalho que têm produzido graves consequências para a saúde mental dos trabalhadores. Estas consequências danosas na psiqué do trabalhador tiveram origem, historicamente, nas diversas transformações ocorridas no mundo do trabalho, tal como a introdução da fragmentação das tarefas no período da manufatura, ainda no século XIX, na separação entre concepção e execução das atividades laborais, introduzida pelos modelos taylorista e fordista, e, mais recentemente, nas mudanças promovidas pela incorporação dos modelos ditos "flexíveis" (como o "toyotismo"), que passaram a demandar um trabalhador mais engajado para realizar diversas operações e muito mais submetido aos complexos processos produtivos. 
O 'taylorismo', criado pelo engenheiro Frederick Taylor, é um sistema baseado na divisão do trabalho e na especialização do operário em uma única tarefa. De acordo com os princípios tayloristas, o trabalhador não teria mais a necessidade de conhecer todo o processo de produção, devendo conhecer apenas uma única atividade relevante em tal processo, desenvolvendo um aperfeiçoamento constante apenas nesta referida atividade. Assim procedendo, o 'taylorismo', simultaneamente aumentava a produção, barateava o preço dos produtos industrializados e ainda contribuía para especializar um operário a um serviço, criando uma 'alienação mental' do empregado, uma vez que não apenas o meio de produção se tornava sistematizado, mas também os horários de trabalho e a cobrança para que o trabalhador sempre possa produzir mais.

O 'fordismo', criado por Henry Ford, o fundador da fábrica de automóveis que leva o seu nome, é uma junção prática do sistema taylorista e associado às facilidades técnicas advindas do aperfeiçoamento produtivo das máquinas. O 'toyotismo', criado após a Segunda Guerra Mundial pelo japonês Taiichi Ohno, é um sistema de produção que foi posto em prática inicialmente na fábrica automotiva da Toyota. Elaborado tendo em conta as limitações de mercado e de estocagem do Japão do pós-Guerra, este novo sistema baseava-se na ideia de produzir de acordo com a demanda existente. Deste modo, o 'toyotismo', passou também a ser conhecido pela expressão inglesa "just-in-time" que significava que a produção era guiada pela necessidade do mercado.

A procura de uma uniformização máxima dos processos produtivos e de método exclusivo de efetivação é oposta à conservação da saúde mental dos operários (DEJOURS, 1996; DEJOURS, 1992; GAULEJAC, 2007; PAGÈS et al, 1987). O contributo pessoal de cada operário à manutenção da qualidade e da produtividade acontece no campo existente entre trabalho prescrito e trabalho real, na oportunidade de intervir de algum modo para ocupar os espaços vazios não antecipados pelas deliberações da administração; para que isto resulte no fortalecimento da identidade e da saúde mental, é forçosa a existência de um reconhecimento desta contribuição, o que não acontece em organizações conduzidas pelo modelo taylorista/fordista.

DEJOURS (1993; 2004) defende que a organização taylorista/ fordista ocasiona a desapropriação do saber do trabalhador, dificultando também qualquer iniciativa de organização e de adequação ao trabalho, pois tal adaptação exige uma atividade intelectual e cognitiva não desejada pelo taylorismo. Sendo assim, para suportar a monotonia do trabalho repetitivo e sem espaço para a criatividade o trabalhador cria mecanismos de defesa específicos. O mais importante deles é o mecanismo de autoaceleração, criado para fazer cessar o pensamento e, com ele, a consciência do desconforto, o sujeito se auto acelera, trabalhando em ritmo excessivo que em longo prazo pode trazer problemas para sua saúde. 
A flexibilização é analisada por alguns atores como uma das principais características do trabalho contemporâneo e a precarização e o desemprego como resultados desse processo. (BAUMAN, 2000; CASTELLS, 1999; GORZ, 1987). Envolve várias estratégias implementadas com a reestruturação produtiva com o objetivo de alterar regulamentações do mercado e das relações de trabalho. (HOLZMANN e PICCININI, 2006)

A acumulação flexível, iniciada nos anos 1970, na transição do modelo fordismo-keynnesiano é marcada pela confrontação direta com a rigidez do fordismo e se apoia na flexibilidade dos processos de trabalho, dos mercados e trabalho, dos produtos e padrões de consumo. Envolve rápidas transformações dos padrões do desenvolvimento que gera vários tipos de desigualdades entre setores e regiões, gerando um vasto movimento no mundo do trabalho denominado "setor de serviços", bem como conjuntos industriais novos. Esse contexto levou ao desaparecimento de postos de trabalho em larga escala e ao mesmo tempo reforçou novas formas de contrato de trabalho caracterizadas pela não regulamentação, tempo parcial, tempo determinado e subcontratações, assim como formas não assalariadas de inserção, ligadas às denominadas economias informais que inclui o trabalho autônomo. Percebe-se também a expansão de modalidades distintas de emprego, como as de jornadas flexíveis, terceirizações e o aumento da informalidade e do desemprego. (HARVEY, 2006)

Essa flexibilização envolve também o mercado consumidor e não apenas as formas de produção e de emprego. "Trata-se de transformar as formas de reprodução, ou seja, todas as relações sociais que sustentam a repõem as relações de produção, para que a nova lógica de acumulação do capital possa se tornar hegemônica". (LANCMAN e UCHIDA, 2003)

DEJOURS (1999), ao analisar o processo de precarização do trabalho, compara a atual situação do mundo do trabalho a uma nova Guerra Mundial, em que a competição torna-se cada dia mais acirrada, ainda mais impulsionada pelo desemprego estrutural, que leva os trabalhadores - empregados e desempregados - a um estado de tensão e sofrimento com a ameaça da demissão presente o tempo inteiro. $\mathrm{O}$ autor analisa o processo de banalização da injustiça social, que trata da utilização propositada desses temores por parte de gestores como técnica de administração de pessoas, com exigências e demandas impossíveis de serem alcançadas humanamente falando. Diante disso, muitos trabalhadores empregam esforços demasiados para cumprir metas impostas pela organização do trabalho, gerando uma pressão insuportável para ele. Surgindo um sofrimento, que Dejours vai chamar de sofrimento patogênico.

\section{ORGANIZAÇÃO DO TRABALHO}

O objeto de estudo da PdT são as relações dinâmicas estabelecidas entre a organização do trabalho e os processos manifestos pelos sujeitos em suas vivências de prazer e de sofrimento desenvolvidas 
em suas atividades laborais, as estratégias de ação elaboradas pelos mesmos para mediar as contradições surgidas na organização do trabalho, as patologias sociais envolvidas, assim como a própria saúde e o adoecimento no trabalho. A análise desenvolvida neste novo campo interdisciplinar é dirigida, assim, aos processos intersubjetivos que possibilitam a gestão social das interpretações do trabalho feito pelos sujeitos e que são produtoras potenciais de atividades, de 'saber fazer' e de novas maneiras de executar as diversas operações no trabalho (DEJOURS, 1993).

Nesta abordagem teórica da PdT ressalta-se a importância capital da organização do trabalho, aqui interpretada como sendo o fator decisivo das experiências vivenciadas de prazer e de sofrimento. Dá-se também um relevo fundamental às condições de realização do trabalho e que podem vir a transformá-lo em uma coisa prazerosa e enriquecedora da identidade do trabalhador ou, em contraposição, transformá-lo em uma experiência de vida árdua e dolorosa que conduz quase sempre ao sofrimento. A organização do trabalho para DEJOURS (1987) exerce sobre o homem uma ação específica, cujo impacto é o aparelho psíquico. Em certas condições emerge um sofrimento que pode ser atribuído ao choque entre uma história individual, portadora de projetos, de esperanças e de desejos e uma organização do trabalho que os ignora.

Esse sofrimento deriva da confrontação existente da subjetividade do trabalhador frente aos limites impostos pelas: condições socioculturais e ambientais nas quais o seu trabalho é realizado; pelas relações sociais e pela própria forma de organização do trabalho, que são todas, em conjunto, as consequências de um modo de produção bastante peculiar (MENDES e MORRONE, 2002).

Para DEJOURS (2012, p. 48):

A relação específica entre o sujeito e a organização do trabalho constitui o centro de gravidade de análise. O sujeito é aqui visto dentro destas relações com o coletivo, sob duplo enfoque: dos procedimentos defensivos contra o sofrimento do trabalho, que justamente articulam as produções deste indivíduo àquela do coletivo; da ressonância simbólica que articula o teatro privado da história singular do sujeito ao teatro atual e público do trabalho, abrindo assim uma problemática socialmente referenciada da sublimação e do prazer no trabalho.

Para a PdT, o sofrimento no trabalho surge quando a relação do trabalhador com a organização do trabalho é bloqueada em virtude das dificuldades de negociação das diferentes forças que envolvem o desejo da produção e o desejo do trabalhador. Nesse sentido, ao reconhecer o trabalho, ora como meio para se construir a identidade, ora como fonte de alienação, a PdT direciona o estudo do sofrimento para a inter-relação dos trabalhadores com a organização do trabalho e para as estratégias defensivas que utilizam para lidar com o trabalho. 
DEJOURS (1994) conceitua organização do trabalho como a divisão do trabalho, o conteúdo da tarefa, o sistema hierárquico, as modalidades de comando e as relações de poder. Essa organização está relacionada diretamente às normas e regras de trabalho delegadas ao trabalhador. No seu interior existem contradições entre o exigido e a possibilidade de execução real do trabalho por parte do trabalhador. As questões relativas à divisão e conteúdo de tarefas, sistema hierárquico e relações socioprofissionais deverão ser construídas com a possibilidade de ser considerado como o lugar de satisfação sublimatória, quando o trabalhador transfere sua energia pulsional, inicialmente apontada para as figuras parentais com o intuito de satisfação imediata, para as relações sociais com satisfação altruísta.

A diferença entre organização de trabalho real e organização de trabalho prescrita é explicada por Dejours (1994) assinalando seus significados para o psiquismo do trabalhador, podendo resultar em uma espécie de prisão psíquica. Para MORGAN (1996), a organização do trabalho é comparada a prisões psíquicas, devido ao auto confinamento que leva o trabalhador às formas de raciocínios preestabelecidos, sem possibilidade de escolha.

É a partir da organização do trabalho que se constrói a relação intersubjetiva e social, pautada por negociações e compromissos entre os sujeitos, tornando-se também objeto de um complexo jogo de relações sociais de trabalho (DEJOURS e ABDOUCHELI, 1994; e DEJOURS e JAUET, 1994). A subjetividade possui uma importância e influência fundamental para a organização do trabalho, podendo ser observada essa relação nas manifestações psicoafetivas individuais e coletivas (MORGAN, 1996; e DEJOURS, 1995). Portanto,

a relação do homem com a organização é a origem da carga psíquica do trabalho. Uma organização do trabalho autoritária, que não oferece uma saída apropriada à energia pulsional, conduz a um aumento de carga psíquica. (DEJOURS, 1994, p.30).

Assim, deve-se considerar que o estudo psicodinâmico da relação homem/trabalho que conduz às vivências de prazer-sofrimento advindas da organização do trabalho é dialético, portanto, não devem ser estudadas separadamente. Podemos então identificar, elementos característicos da organização do trabalho que decorrem uma ou outra vivência juntamente com a dinâmica que delas procedem, através da fala dos trabalhadores, da análise da palavra advinda do discurso manifesto e latente, palavra essa que se estabelece como mediadora entre as representações psíquicas e a realidade. 


\section{ESTRATÉGIAS DE DEFESA}

Entre a organização do trabalho e o funcionamento psíquico se interpõem estratégias defensivas. DEJOURS (1996) classifica essas estratégias como: defesas construídas pelo coletivo de trabalhadores; Ideologias defensivas de profissão; e defesas individuais (repressão pulsional).

DEJOURS e ABDOUCHELI (1994) conceituam essas aludidas estratégias defensivas como sendo os mecanismos desenvolvidos pelos trabalhadores visando a anular ou ao menos atenuar a percepção da realidade que lhes causa sofrimento. Esses mecanismos defensivos de sobrevivência são uma função das condições externas e são mantidos ao se estabelecerem como um consenso nas práticas de um agrupamento particular de trabalhadores. Esses mecanismos de defesa mudam, entretanto, conforme o modo de organização do trabalho e, deste modo elas assumem formas variadas dentre as diversas categorias profissionais.

As estratégias defensivas construídas pelos trabalhadores passaram a ser a principal mudança desse enfoque da psicopatologia do trabalho, principalmente as defesas construídas pelo coletivo, denominadas de defesas coletivas e de ideologias defensivas de profissão. As defesas individuais, trabalhadas pela Psicopatologia e pela Psicanálise também realizam um papel fundamental para enfrentamento de situações no trabalho. Outra questão analisada pelo autor diz respeito ao surgimento de doenças físicas como defesa em resposta a pressões nas organizações. A investigação dessas doenças (estudo da psicossomática) também faz parte da investigação da psicopatologia, que não se limita à saúde mental, mas também a física, como fenômeno com o nome de stress.

Para DEJOURS (2012), a carga psíquica do trabalho está contida na organização do trabalho como resultado da confrontação do desejo do trabalhador à imposição do empregador. Geralmente essa carga psíquica de trabalho aumenta quando a liberdade de organização do trabalho diminui e essa regra é modulada pelo jogo da livre escolha do ofício. Segundo o autor, "quando não há mais arranjo possível da organização do trabalho para o trabalhador, a relação conflitual do aparelho psíquico é bloqueada. Abre-se, então, o domínio do sofrimento". (DEJORUS, 2012, p.27).

As estratégias defensivas podem ser definidas como um mecanismo utilizado pelos trabalhadores com o objetivo de modificar, transformar e minimizar a sua percepção da realidade causadora do sofrimento. É um processo subjetivo, considerando que ele não modifica essa realidade de pressão patogênica imposta pela organização do trabalho.

O que diferencia as estratégias coletivas de defesa das estratégias individuais um mecanismo de defesa individual do coletivo é que as individuais permanecem no indivíduo sem a presença física do objeto, enquanto, que as coletivas estão condicionadas às condições externas 
e depende do consenso de um grupo de trabalhadores específico. (MENDES, 1999).

DEJOURS e ABDOUCHELI (2009, p. 128) tratam essas estratégias coletivas de defesa:

[...] essas defesas levam à modificação, transformação e, em geral, à eufemização da percepção que os trabalhadores têm da realidade que os faz sofrer. [...] minimizar a percepção que eles têm dessas pressões, fontes de sofrimento [...] funcionam como regras [...] supõem um consenso ou um acordo partilhado [...] A regra é de fato possuída pelos indivíduos coletivamente [...] as estratégias coletivas de defesa atuam, como já foi dito, sobre a percepção da realidade e operam por retorno e eufemização.

As estratégias coletivas de defesa ajudam o indivíduo a suportar uma realidade que isoladamente com as suas defesas individuais ele não conseguiria suportar. Nesse sentido de coletividade, os indivíduos se unem para construir uma estratégia defensiva comum, que passa a funcionar como regras com anuência de todos e que no momento que desejarem pode ser interrompida. (DEJOURS, 2009). Essas estratégias coletivas de defesa só se sustentam com o consentimento dos outros e depende de condições externas, enquanto as defesas individuais são intrínsecas ao indivíduo, persistindo mesmo sem a presença dos outros e permanecem independentes da influência do meio externo.

Para que os sistemas coletivos funcionem, portanto, é necessária a construção de regras, determinadas e reguladas através de acordos entre os membros de um grupo de trabalhadores. Essas regras podem deixar de funcionar a partir do instante em que os sujeitos não queiram mais a elas se submeter. Para o trabalhador, o não cumprimento dessas regras pode significar entrar em um processo de exclusão do coletivo.

Outro fator importante analisado nos estudos de campo de DEJOURS (1990) mostra que o os procedimentos defensivos do trabalhador são explorados pela organização do trabalho, ou seja, podem ser utilizados em proveito da produtividade. As estratégias coletivas de defesa servem como um sistema de seleção psicológica nas organizações, separando os que contribuem com as estratégias e eliminando os que hesitam às adaptações. $\mathrm{O}$ autor também afirma que nas pesquisas mais recentes, pode-se observar que a prática dos procedimentos defensivos vai além da adaptação às pressões rígidas, mas também ela contribui sensivelmente para a evolução da própria organização do trabalho.

\section{DEFESAS COLETIVAS DOS SERVIDORES DE UMA UNIVERSIDADE PÚBLICA}

Apresentamos abaixo um quadro com as falas dos entrevistados que revelam as condições ambientais, as condições socioprofissionais e as defesas coletivas utilizadas por eles. Esses dados sinalizam a precarização das condições de trabalho que caracterizam o modo de organi- 


\section{Revista de Gestão Pública}

zação que levam os servidores a desenvolverem defesas para lidar com a situação. Essas defesas estão sempre relacionadas às condições externas do sujeito e depende do consenso dos trabalhadores.

QUADRO 01 - Relatos dos servidores técnico-administrativos de uma universidade pública sobre a organização do trabalho e a construção dos procedimentos defensivos coletivos

\begin{tabular}{|c|c|}
\hline ENTREVISTADOS & CONDIÇÕES AMBIENTAIS \\
\hline Sujeito 1 & $\begin{array}{l}\text { Na estrutura física eu estou bem, tem material, poucas vezes não tem em estoque. O ambiente é ótimo. Tem dias que eu } \\
\text { fico até mais tarde e não tenho dificuldade nenhuma com o ambiente. }\end{array}$ \\
\hline Sujeito 2 & $\begin{array}{l}\text { Precisa melhorar muito. Não temos site. Tudo o aluno depende da gente. Tem muito papel, é uma coisa desordenada. } \\
\text { A estrutura física precisa melhorar muito. O arquivo é muito ruim, as cadeiras são horríveis e o próprio colega quebra. } \\
\text { Todo dia eu saio catando os meus materiais de trabalho e os próprios colegas da tarde quebram. } \\
\text { Os equipamentos até que funcionam. }\end{array}$ \\
\hline Sujeito 3 & $\begin{array}{l}\text { Todas as coisas estão cooperando para o bom desempenho das atividades. Essas coisas, infraestrutura, climatização, } \\
\text { tecnologia são boas. }\end{array}$ \\
\hline Sujeito 4 & $\begin{array}{l}\text { Eu não estou satisfeito, estou aqui há quatro meses, mas observo a falta de condições estruturais. O computador é muito } \\
\text { lento, o ar condicionado não funciona direito. Não tem nem bolsista nem computador apropriado. }\end{array}$ \\
\hline Sujeito 5 & $\begin{array}{l}\text { O Centro em que eu trabalho está muito sucateado de uma maneira geral. A estrutura física é péssima, pois além de ser } \\
\text { um ambiente feio, ele tem problemas de ventilação, umidade, poeira, goteira quando chove. O meu departamento já } \\
\text { ficou alagado num período de chuvas. Os equipamentos são muito ultrapassados, mas dá para fazer o trabalho. Temos } \\
\text { problemas constantes com impressoras e temos que dar o nosso jeito, pedindo para imprimir em outros setores ou } \\
\text { tentando a gente mesmo consertar, porque a visita de um técnico é uma coisa muito demorada e a demanda de trabalho } \\
\text { nem sempre espera. }\end{array}$ \\
\hline ENTREVISTADOS & CONDIÇÕES SOCIOPROFISSIONAIS \\
\hline Sujeito 1 & $\begin{array}{l}\text { Com os meus colegas de trabalho e com a bolsista é ótimo, o serviço flui, mas tem uma colega de trabalho que eu } \\
\text { tenho muita dificuldade de colocar o funcionamento de serviço. É apenas unilateral, e às vezes eu sou cobrada por } \\
\text { um determinado serviço que não está diretamente ligada à minha função e eu tenho que dar conta e como não há essa } \\
\text { interação, torna-se difícil, muito difícil. Já houve uma conversa com a coordenadora e melhorou um pouco, mas no todo } \\
\text { isso é muito insuficiente. } \\
\text { Com a coordenadora, ela mistura a coisa, porque eu não tenho a função de secretária e muitas vezes ela pede a mim } \\
\text { coisas de secretária. } \\
\text { O único problema é que a informação com relação ao serviço não é repassada, o que torna difícil o trabalho. }\end{array}$ \\
\hline
\end{tabular}




\section{Revista de Gestão Pública}

PRÁTICAS E DESAFIOS

ISSN: 2177-1243

\begin{tabular}{|c|c|}
\hline Sujeito 2 & $\begin{array}{l}\text { É tudo bem. A gente cobre um ao outro. Quando tem uma bronca a gente mesmo resolve. } \\
\text { Com relação ao chefe eu não tenho o que dizer por que ele não vem quase aqui. Com os alunos o relacionamento é } \\
\text { maravilhoso. Os professores também têm um bom relacionamento. Entre eles, eles se comem, mas com os técnicos o } \\
\text { relacionamento é direitinho. } \\
\text { No setor anterior a esse a minha chefe me chamou e disse que não dava mais e que eu arrumasse um lugar para onde ir. } \\
\text { No outro setor anterior a esse eu também fui tirada do setor sem a menor explicação e eu me senti usada em um jogo de } \\
\text { poder de diretores e eu fiquei no meio. } \\
\text { Eu soube que o único problema era que eu quando chegava no setor eu limpava os birôs e colocava os papéis sem } \\
\text { importância no lixo. } \\
\text { Na oportunidade o meu chefe abriu a minha bolsa, jogou os meus pertences no chão e disse: "rua, aqui você não trabalha } \\
\text { mais". } \\
\text { O pró-reitor me chamou para uma conversa e me deixou no Departamento, mas eu senti que fui usada apenas para uma } \\
\text { demonstração de poder. }\end{array}$ \\
\hline Sujeito 3 & $\begin{array}{l}\text { O meu relacionamento é politicamente correto, embora tenhamos que respeitar as diferenças que não são poucas. } \\
\text { Diferenças de pensamento, de religião, política, todas possíveis, opções sexuais. Todas têm que se respeitar, porque as } \\
\text { diferenças não são poucas. } \\
\text { Existem os momentos de estranhamento, mas geralmente o relacionamento é o melhor possível. }\end{array}$ \\
\hline Sujeito 4 & $\begin{array}{l}\text { Hoje eu aprendi que eu devo me ater a ter um relacionamento formal. Não dá para ser amigo com o chefe, mas eu não } \\
\text { gosto, porque eu sempre tive amizade com o meu chefe, ter uma relação calorosa, mas não estou conseguindo com a } \\
\text { chefe atual que eu tenho a mais de dois meses. Ela tem uma visão escravocrata. Eu não gosto dessa forma de gestão de } \\
\text { muita cobrança. } \\
\text { Eu queria uma relação de aliança e respeito. } \\
\text { Com pouco tempo e eu não estou me sentido bem, mas não vou fugir dessa vez. } \\
\text { Fiz um planejamento anual e ela não respondeu. } \\
\text { Acho que ela não gosta que eu seja protagonista, eu não sou de ficar esperando ordens e acho que vou ter muitos } \\
\text { problemas, mas ninguém é eterno. } \\
\text { O que fica é que o ambiente seja adequado de se trabalhar. }\end{array}$ \\
\hline
\end{tabular}




\section{Revista de Gestão Pública}

\begin{tabular}{|c|c|}
\hline Sujeito 5 & $\begin{array}{l}\text { Com relação aos colegas a relação é boa, mas com probleminhas que surgem de vez em quando. Tem colegas que não } \\
\text { querem cumprir horário e gostam de se escorar. O professor, que é o profissional principal da instituição, muitas vezes } \\
\text { fica prejudicado com a falta de competência dos colegas técnico-administrativos. } \\
\text { A minha relação com o chefe e professores é muito boa. Eu respeito a posição deles como superior à minha, porque } \\
\text { estamos falando de uma instituição de ensino, então o professor é o profissional principal da instituição, por isso ele é } \\
\text { superior aos outros e devemos tratá-lo com respeito. }\end{array}$ \\
\hline ENTREVISTADOS & PROCEDIMENTOS DEFENSIVOS \\
\hline Sujeito 1 & $\begin{array}{l}\text { Hoje não, mas aconteceu em outro setor que eu trabalhei eu chamei uma colega para trabalhar comigo e quando ela } \\
\text { chegou virou minha inimiga. Ela virou-se contra mim, ficava falando da minha vida pessoal, provocando discussão, e eu } \\
\text { terminei saindo do setor por causa dessa colega que eu saí do setor anterior. } \\
\text { Eu me arrependi amargamente de ter ajudado essa colega, mas eu contei a todo mundo o meu problema e o que ela } \\
\text { havia feito comigo. } \\
\text { Hoje eu não ajudo mais ninguém. Quando alguém vem me contar algum problema de trabalho, eu escuto e fico quieta. } \\
\text { Nesse período isso afetou a minha vida em casa, porque eu tinha filhos pequenos e uma mãe doente, então eu saí para } \\
\text { não afetar a minha saúde. Eu saí antes de adoecer e ficava mal-humorada, mas eu acho que não adoeci porque eu abri a } \\
\text { boca e saí falando para todo mundo. } \\
\text { Depois de } 15 \text { anos naquele setor eu fui chamada sem nenhum diálogo para um setor que eu não sabia. Eu não obedeci a } \\
\text { ordem, arrumei outro setor e pedi remoção para o setor que eu queria. Foi difícil porque o setor de pessoal queria fazer } \\
\text { cumprir a ordem da chefe sem saber se eu estava satisfeita. } \\
\text { Eu fui ao Reitor para conversar a minha situação, falei com o chefe do gabinete e ele resolveu a situação intermediando } \\
\text { com o setor de pessoal. } \\
\text { Em parte, estou satisfeita, por causa dos problemas citados anteriormente da colega colaborativa. Já tentei ir para } \\
\text { outros setores, fui convidada inclusive para outros setores, mas a chefia atual não liberou porque não tem pessoal para } \\
\text { substituir, não tem permuta. } \\
\text { Ele mandou parar de procurar um lugar para sair porque a impressão de que você quer sair do seu setor e eu respondi } \\
\text { que eu quero sair daqui. } \\
\text { Outro motivo foi que mudaram o meu horário, apenas me comunicando e eu já havia negociado quando vim trabalhar } \\
\text { no setor atual o meu horário de trabalho. Eu tento resolver esse problema de horário estendendo alguns dias o meu } \\
\text { horário de trabalho. Eu encontrei um equilíbrio entre o que a chefia queria e o que eu queria. }\end{array}$ \\
\hline
\end{tabular}




\section{Revista de Gestão Pública}

PRÁTICAS E DESAFIOS

ISSN: 2177-1243

\begin{tabular}{|c|c|}
\hline Sujeito 2 & $\begin{array}{l}\text { Foi quando a minha chefe me chamou e disse que não dava mais e que eu arrumasse um lugar para onde ir. } \\
\text { No outro setor anterior a esse eu também fui tirada do setor sem a menor explicação e eu me senti usada em um jogo de } \\
\text { poder de diretores e eu fiquei no meio. } \\
\text { Eu soube que o único problema era que eu quando chegava no setor eu limpava os birôs e colocava os papéis sem } \\
\text { importância no lixo. } \\
\text { Na oportunidade o meu chefe abriu a minha bolsa, jogou os meus pertences no chão e disse: "rua, aqui você não trabalha } \\
\text { mais". } \\
\text { O pró-reitor me chamou para uma conversa e me deixou no Departamento, mas eu senti que fui usada apenas para uma } \\
\text { demonstração de poder. } \\
\text { Mas daí eu já percebi que não queria continuar como contadora. } \\
\text { Eu fiquei um tempo subutilizada no setor por um tempo e depois eu fui aproveitada no novo setor como contadora, e } \\
\text { quando eu tive uma oportunidade eu pedi para sair de lá. } \\
\text { Hoje eu estou satisfeita com o que faço. Era o que eu queria fazer aqui. }\end{array}$ \\
\hline Sujeito 3 & $\begin{array}{l}\text { Aqui no Departamento eu trabalho desde 2011, mas já trabalhei em vários lugares. } \\
\text { Os motivos que eu saí desses lugares foi o Hospital Universitário, porque eu contraí pneumonia por causa das bactérias } \\
\text { e eu sou alérgico. } \\
\text { Da Reitoria sai porque passei no curso de especialização no CE e fui trabalhar lá. } \\
\text { Por incompatibilidade com a coordenadora, das nossas ideias eu preferi vir para o Centro de Artes. Eu dava uma ordem } \\
\text { aos bolsistas e ela dava outra ordem. Ela tirava os bolsistas para dar assistência nos projetos dela e eu tinha que fazer o } \\
\text { trabalho deles. Isso gerou conflitos e não teve condiçôes e eu saí. } \\
\text { Ela queria ficar no meu lugar, coordenar os bolsistas e antes de discutir eu saí. }\end{array}$ \\
\hline Sujeito 4 & $\begin{array}{l}\text { Eu não gosto dessa forma de gestão de muita cobrança. } \\
\text { Eu queria uma relação de aliança e respeito. } \\
\text { Com pouco tempo e eu não estou me sentido bem, mas não vou fugir dessa vez. } \\
\text { Depois da TV da Universidade eu andei por muitos outros setores, }\end{array}$ \\
\hline
\end{tabular}




\section{Revista de Gestão Pública}

Eu passei por muitos altos e baixos de motivação com relação ao meu trabalho. Aqui o chefe muda de dois ou quatro anos, quando ele é reconduzido, então tem chefe bom e chefe ruim. Quando a gente pega um chefe ruim, fica difícil e muitas vezes a única solução é procurar outro setor para trabalhar senão a gente acaba adoecendo mesmo.

Como eu expliquei anteriormente, eu precise pedir para sair de dois setores que eu não estava satisfeita.

O primeiro porque eu não gostava do que fazia, na verdade do que não fazia, pois passava a maior parte do tempo ociosa. A chefe não queria me liberar, eu passei um ano negociando, até que finalmente ela me liberou.

No outro setor eu tive problemas com uma colega de trabalho e acabamos discutindo por questões de trabalho mesmo, e como a relação com ela já vinha se complicando e eu também já tinha conversado com o chefe para sair, depois da discussão, ela fez a minha caveira ao chefe e ele me liberou sem permuta.

Eu mudei outras vezes, mas a convite para assumir cargos de confiança.

Nos relatos dos participantes da pesquisa, podemos identificar várias dificuldades com relação à estrutura física. Três dos cinco entrevistados, apresentaram dificuldades, porém, de acordo com os relatos dos Sujeitos 2 e 5, eles mesmo tentam resolver algumas situações de precarização: "Todo dia eu saio catando os meus materiais de trabalho e os próprios colegas da tarde quebram" (Sujeito 2)."Temos problemas constante com impressoras e temos que dar o nosso jeito, pedindo para imprimir em outros setores ou tentando a gente mesmo consertar" (Sujeito 5).

Com relação às condições socioprofissionais, o Sujeito I reclama a falta de comunicação com a colega de trabalho, dificultando assim a realização as tarefas: "O único problema é que a informação com relação ao serviço não é repassada, o que torna difícil o trabalho." (Sujeito 1). Já o Sujeito 4 revela uma gestão baseada em cobrança e pressão para o cumprimento das tarefas. Referindo-se à sua chefe ele afirma: "Ela tem uma visão escravocrata. Eu não gosto dessa forma de gestão de muita cobrança. (...) Acho que ela não gosta que eu seja protagonista, eu não sou de ficar esperando ordens e acho que vou ter muitos problemas" (Sujeito 4). O Sujeito 5 está insatisfeito apenas com situações que ele coloca em relação aos seus pares: "Tem colegas que não querem cumprir horário e gostam de se escorar" (Sujeito 5).

No que diz respeito às estratégias coletivas de defesa utilizadas pelos servidores de uma universidade pública, podemos perceber como resultado desta pesquisa, que existe um consenso entre os entrevistados de recorrer ao sistema de remoção de pessoal da instituição como forma de "resolver" os problemas enfrentados ou "fugir" dos mesmos.

O Sujeito 1 ao relatar mais de um problema interpessoal, colocou a remoção como estratégia para solucionar o problema: "Ela virou-se contra mim, ficava falando da minha vida pessoal, provocando discussão, e eu terminei saindo do setor por causa dessa 
colega. (...) Eu sai antes de adoecer e ficava mal-humorada, mas eu acho que não adoeci porque eu abri a boca e saí falando para todo mundo." Em outra situação o Sujeito I revela: "Depois de 15 anos naquele setor eu fui chamada sem nenhum diálogo para um setor que eu não sabia. Eu não obedeci a ordem, arrumei outro setor e pedi remoção para o setor que eu queria". O Sujeito 1 ainda afirma que atualmente solicitou à sua chefia várias vezes para sair do setor, possivelmente como estratégia para resolver o seu problema de insatisfação relatada por ela nas condições socioprofissionais acima: "Ele mandou parar de procurar um lugar para sair porque a impressão de que você quer sair do seu setor e eu respondi que eu quero sair daqui."

O Sujeito 02 também revela que a remoção também foi utilizada pela sua chefe como forma de punição: "Foi quando a minha chefe me chamou e disse que não dava mais e que eu arrumasse um lugar para onde ir. No outro setor anterior a esse eu também fui tirada do setor sem a menor explicação e eu me senti usada em um jogo de poder de diretores e eu fiquei no meio. (...) O pró-reitor me chamou para uma conversa e me deixou no Departamento, mas eu senti que fui usada apenas para uma demonstração de poder." Ela afirma que a saída para lidar com a situação de sofrimento foi a remoção também: "(...) e quando eu tive uma oportunidade eu pedi para sair de lá."

Com relação ao Sujeito 3, a situação se repete ao lidar com problemas interpessoais em setores anteriores: "Por incompatibilidade com a coordenadora, das nossas ideias eu preferi vir para o Centro de Artes. (...) Ela tirava os bolsistas para dar assistência nos projetos dela e eu tinha que fazer o trabalho deles. Isso gerou conflitos e não teve condições e eu saí. Ela queria ficar no meu lugar, coordenar os bolsistas e antes de discutir eu sai."

Já o Sujeito 4 preferiu não entrar em detalhes sobre as situações que o levaram a mudar várias vezes de setor: "Depois da NTVRU eu andei por muitos outros setores". Porém, ele deixa claro que está insatisfeito com o seu setor atual devido à relação com a sua chefia, mas ele está tentando usar outra estratégia para não recorrer ao processo de remoção: "Eu não gosto dessa forma de gestão de muita cobrança. Eu queria uma relação de aliança e respeito. Com pouco tempo e eu não estou me sentido bem, mas não vou fugir dessa vez."

Para o Sujeito 5, a remoção tornou-se a única saída para lidar com problemas interpessoais que lhe causava sofrimento: "Ainda bem que eu consegui sair do setor que estava me fazendo mal. Depois de esperar um ano lutando para sair do setor, finalmente uma colega me ajudou e eu consegui. (...) Quando a gente pega um chefe ruim, fica difícil e muitas vezes a única solução é procurar outro setor para trabalhar senão a gente acaba adoecendo mesmo."

Pelos relatos dos entrevistados, pode-se perceber que os principais problemas relacionados à organização do trabalho se referem às questões interpessoais, tanto com colegas de trabalho quanto na relação chefe/subordinado. Todos os entrevistados, pré-selecionados pelo tempo de serviço acima de dez anos na instituição e que passaram por situações de remoção, têm características em comum de utilizar esse processo de remoção para solucionar suas dificuldades relacionais. $\mathrm{O}$ Sujeito 3 chegou a pedir remoção como prevenção de problemas com 
a sua chefe. Já o Sujeito 4 relatou que está passando por situação de sofrimento, mas que vai encarar a situação sem pedir remoção: "eu não vou fugir dessa vez". O termo "fuga" deixa claro que a remoção já foi por ele utilizada ("eu já andei por muitos outros setores") para sair de uma situação conflituosa. O Sujeito 5 utiliza a hipérbole lutando como figura de linguagem (ideia exagero de forma intencional) - "Depois de esperar um ano lutando para sair" - para enfatizar a sua tentativa de sair do local de trabalho. Ele tentou de todas as maneiras possíveis, pois tinha um compromisso real de sair do local de trabalho.

No momento em que os trabalhadores estruturam as suas defesas, eles resistem em questioná-las, isso pode ser observado quando o conjunto dos entrevistados relatam suas andanças por diversos setores da universidade estudada, como estratégia para mitigar seus sentimentos de angústia.

As narrativas apresentadas pelo conjunto dos entrevistados nos proporcionam observar a instalação do processo de alienação, em que a estratégia defensiva da remoção pode tornar-se tão preciosa para si mesmo, a ponto de ser transformada em objeto, rotina, em um recurso automático. Quando se chega a esse ponto, o sofrimento passa a ser visto como resultado do enfraquecimento das defesas e não como consequência do trabalho. Dessa forma, a estratégia de defesa da remoção que não era vista como nada além de uma defesa contra o sofrimento, passa ser vista como uma promessa de felicidade, ou um novo ponto de partida, uma expectativa de nova chance de felicidade para estes sujeitos.

A remoção, como um tipo de estratégia de fuga por parte dos entrevistados, assume aqui um papel destinado ao não questionamento, a uma postura acrítica de sua própria subjetividade. Se assemelha ao que PAGÈS et al (2008) falam em dissolução da instância crítica, situação em que a organização, no caso aqui estudado, uma universidade pública, é perfeita e tudo o que ela faz é bom e irrepreensível. Em caso de conflito entre o indivíduo e a organização, o indivíduo tenderá a retornar a agressão contra si próprio, a se deprimir, a se sentir culpado, ao invés de ressignificar e alterar sua relação subjetiva com a organização, como intuito de resgatar sua altivez e autoconfiança.

\section{CONSIDERAÇÕES FINAIS}

O presente estudo teve o objetivo pesquisar como os servidores de uma universidade pública estão se mobilizando para lidar com as suas rotinas de trabalho e as dificuldades relacionadas à organização do trabalho. Os problemas são de ordem estrutural e principalmente dificuldades socioprofissionais, que levam esses trabalhadores à situação de sofrimento e insatisfação.

Os resultados da pesquisa apontam que, para lidar com essa situação, os servidores constroem e utilizam estratégias de remoção e modos de enfrentamento para transformar o sofrimento em prazer e evitar o adoecimento. Evidencia-se, através das narrativas, que os ser- 
vidores dessa universidade enfrentaram ou enfrentam conflitos interpessoais com os colegas de trabalho ou com seu chefe e utilizam a remoção como forma de enfrentamento, como uma estratégia defensiva coletiva para lidar com esse sofrimento. Alguns deles relatam situação de adoecimento como consequência do sofrimento vivenciado. Nessa perspectiva, a remoção para esses servidores é a condição principal de "fuga", a "solução" e a "única saída" para a transformação de uma situação de angústia e sofrimento no trabalho em uma expectativa de obtenção de felicidade ou prazer no novo ambiente de trabalho .

Com os resultados das entrevistas, podemos, ainda, caracterizar alguns aspectos na relação de entre servidores técnico-administrativos e docentes da universidade pública estudada. Essa relação de hierarquização, aceita por uns e denunciada por outros como uma relação rotineira entre essas categorias profissionais, revela uma ideologia defensiva para aqueles que aceitam como "natural" essa relação de hierarquização. Essa ideologia tem o objetivo de mascarar, de ocultar o sofrimento desses trabalhadores, como justificativa pelo não reconhecimento da importância do seu trabalho.

Nos relatos dos sujeitos, podemos perceber um conflito na relação entre técnico-administrativos e docentes. Há uma clara divisão na forma de enxergar essa relação - a não aceitação da superioridade imposta pelos docentes por uns e a aceitação da condição de superioridade do docente por outros. Essa ambiguidade gera conflitos não apenas entre as duas categorias, mas dentro da própria categoria de técnico-administrativo, levando ao sofrimento e até mesmo ao recurso da remoção como um tipo de estratégia defensiva. A falta de reconhecimento pelas suas atividades profissionais, que leva consequentemente à falta de sentimento de realização é o principal motivo desencadeador desse conflito e consequentemente desse tipo de resolução do sofrimento por parte dos servidores técnico-administrativos.

Nas entrevistas realizadas com os servidores técnico-administrativos pudemos observar que eles adotam formas peculiares de tais ideologias de forma a mascarar o sofrimento a que se sentem submetidos em suas relações de trabalho. Torna-se, portanto, uma alienação, que mascara o sofrimento e atende a ideologia institucional dominante, levando-os ao uso das defesas psíquicas para manter esse trabalhador produtivo e desconhecedor das causas de sua angústia. Essa ambivalência do sofrimento gera exploração dos modos de subjetivação do trabalhador. As evidência coletadas nas narrativas analisadas, permitem concluir que a estratégia da remoção torna-se um requisito importante para a manutenção do equilíbrio entre desprazer e prazer diante da organização do trabalho, e não respeitar esta estratégia e ainda confrontá-la poderá levar aos sujeitos analisados a correr um sério risco de transportar o sistema de defesa à consequências desagradáveis, podendo desencadear no indivíduo um desequilíbrio emocional estruturador de sua condição diante da organização do trabalho. 


\section{REFERÊNCIAS}

ARENDT, H. (1997). A Condição Humana. 8 ${ }^{\text {a }}$

ed. Rio de Janeiro, Forense Universitária.

BAUMAN, Z. (2000). A modernidade

líquida. Rio de Janeiro, Jorge Zahar.

CASTELLS, M. (1999). A sociedade em rede: a era da informação - economia, sociedade e cultura (v. 1). São Paulo, Paz e Terra.

DEJOURS, C. (2004). In: LANCMAN, S. e SZNELWAR, L. I. Christophe Dejours - Da Psicopatologia à Psicodinâmica do Trabalho. Rio de Janeiro: Ed. Fiocruz, Brasília, Paralelo.

(1999). A banalização da injustiça social.

Rio de Janeiro, Fundação Getúlio Vargas.

(1992). A Loucura do Trabalho: estudo de psicopatologia do trabalho. São Paulo, Cortez-Oboré.

(1996). Uma nova visão do sofrimento humano nas organizações. In: CHANLAT, J. F. (Org.) O Indivíduo na Organização - dimensões esquecidas. 3. ed. São Paulo, Atlas. (2004). Subjetividade, trabalho e ação.

Revista Produção, v. 14, n. 3, p. 27-34, set./dez. Disponível em: http://www.scielo.br/pdf/\%oD/prod/ v14n3/v14n3ao3.pdf [Acesso em o5 jul. 2011.] (2012). ABDOUCHELI, E. e JAYET, C.

Psicodinâmica do trabalho: contribuições da escola dejouriana à análise da relação prazer, sofrimento e trabalho. São Paulo, Atlas.

DEJOURS, C. e ABDOUCHELI, E. (1994). Itinerário teórico em psicopatologia do trabalho. In: DEJOURS, C. e ABDOUCHELI, E. e JAYET, C. Psicodinâmica do Trabalho. São Paulo, Atlas.

GAULEJAC, V. (2007). Gestão como doença social - Ideologia, poder gerencialista e fragmentação social. São Paulo, Idéias \& Letras.

GORZ, A. (1987). Adeus ao proletariado - para além do socialismo. Rio de Janeiro, Forense Universitária.

HARVEY, D. (2006). Condição pós-moderna. São Paulo, Loyola.

HOLZMANN, L. e PICCININI, V. (2006). Flexibilização. In: CATTANI, A. e HOLZMANN, L. Dicionário de trabalho e tecnologia. Porto Alegre, Ed. da Universidade UFRGS.

LANCMAN, S. e UCHIDA, S. (2003). Trabalho e subjetividade - o olhar da Psicodinâmica do Trabalho. Cadernos de 
Psicologia Social do Trabalho, vol. 6, pp. 79-90.

MENDES, A. M. (2007). Psicodinâmica do Trabalho - teoria, método e pesquisas. São Paulo, Casa do Psicólogo.

MENDES, A. M. e MORRONE, C. F. (2010). Trajetória teórica e pesquisas brasileiras sobre prazer e sofrimento no trabalho. In: MENDES, A. M. et al (Orgs.). Psicodinâmica e clínica do trabalho - temas, interfaces e casos brasileiros. Curitiba, Juruá.

MORGAN, G. (1996). Imagens da Organização. São Paulo, Atlas.

PAGÈS, M. et al. (1987). O poder das organizações. São Paulo, Atlas. 